\title{
Correlation Between Ideal Cardiovascular Health Metrics and Plasma hs-CRP Levels in a North China Population: One Four-Year Follow-Up Study
}

This article was published in the following Dove Press journal:

International Journal of General Medicine

\author{
Jia Chen' \\ Liuyue $\mathrm{Xu}^{2}$ \\ Quan $\mathrm{He}^{3}$ \\ Shouling $\mathrm{Wu}^{4}$ \\ Dayi $\mathrm{Hu}^{5}$ \\ Kai Lu ${ }^{3}$ \\ 'Department of Clinical Nutrition, The \\ First Affiliated Hospital of Chongqing \\ Medical University, Chongqing 4000I6, \\ People's Republic of China; ${ }^{2}$ Department \\ of Hematology, The First Affiliated \\ Hospital of Chongqing Medical University, \\ Chongqing 400016, People's Republic of \\ China; ${ }^{3}$ Department of Cardiology, The \\ First Affiliated Hospital of Chongqing \\ Medical University, Chongqing 400016, \\ People's Republic of China; ${ }^{4}$ Department \\ of Cardiology, Kailuan General Hospital, \\ Hebei United University, Tangshan \\ 1008I6, People's Republic of China; \\ ${ }^{5}$ Heart Center, Peking University People's \\ Hospital, Beijing 100044, People's \\ Republic of China
}

Background: This prospective cohort study aimed to evaluate the potential association of ideal cardiovascular health metrics with the plasma levels of highly sensitive C-reactive protein (hs-CRP) among people in North China.

Methods: A total of 80,968 participants were included in this study at baseline. Data relating to seven health metrics and plasma hs-CRP levels were collected at baseline and the end of follow-up. The change in health metrics of each individual was compared and recorded. The potential association of gain or loss of each health metric, as well as the change in the total number of health metrics that each individual had during follow-up, with the risk of increased hs-CRP level, were explored by multiple Cox proportional hazards models.

Results: A total of 72,321 participants $(94.51 \%)$ completed the follow-up, and the average follow-up time was 4.1 years. Ideal body mass index (BMI), physical activity, smoking status and total cholesterol all had significant impacts on hs-CRP levels, with ideal BMI having the largest impact. Losing ideal BMI during follow-up raised the probability of hs-CRP increase during the follow-up time by 1.72 (95\% CI, 1.59-1.86) times for men and 2.05 (95\% CI, 1.76-2.39) times for women. The effects of ideal salt intake and blood pressure on hs-CRP levels were uncertain. Changes in the total number of ideal metrics for each individual had a significant cumulative effect on hs-CRP. The hazard ratio of loss of four to six health metrics during follow-up on the risk of hs-CRP increase was 1.69 (95\% CI, 1.38-2.06) for men and 1.52 (95\% CI, 1.13-2.04) for women.

Conclusion: Loss or gain of ideal cardiovascular health metrics is associated with significant fluctuations in plasma hs-CRP levels. The cardiovascular benefits brought by the ideal health metrics are mediated at least in part by reducing systemic inflammation in the body.

Keywords: ideal cardiovascular health metrics, highly sensitive C-reactive protein, cardiovascular diseases

\section{Introduction}

Atherosclerotic cardiovascular disease (ASCVD) has become China's major public health burden, and controlling the incidence of ASCVD has become one of the top priorities for health authorities at all levels in China. ${ }^{1-5}$ In 2010, the American Heart Association (AHA) Committee developed the definition of ideal cardiovascular health to call on citizens to maintain a healthy lifestyle to reduce the incidence of ASCVD. ${ }^{6}$ The ideal cardiovascular health is defined as the simultaneous
Correspondence: Kai Lu

Department of Cardiology, The First Affiliated Hospital of Chongqing Medical

University, No. I, Yixueyuan Road,

Chongqing 4000 I6, People's Republic of

China

Tel/Fax +862389011562

Email lukai2013@foxmail.com
International Journal of General Medicine 2020:13 617-625

617

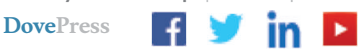

http://doi.org/10.2147/1JGM.S266602 
presence of seven health metrics, namely no smoking, body mass index (BMI) $<25 \mathrm{~kg} / \mathrm{m}^{2}$, physical activity at goal level, diet consistent with current guideline recommendations, untreated total cholesterol (TC) $<200 \mathrm{mg} / \mathrm{dL}$, untreated systolic blood pressure $<120 \mathrm{mmHg}$ and diastolic blood pressure $<80 \mathrm{mmHg}$, and untreated fasting blood glucose $(\mathrm{FBG})<100 \mathrm{mg} / \mathrm{dL}$. Our team's previous work has confirmed that the number of health metrics defined by the AHA is significantly negatively related to the incidence of cardiovascular disease in a Chinese population, ${ }^{7,8}$ but the underlying mechanism is still unclear. A large number of previous studies have shown that mild chronic inflammatory states in the human body can significantly promote the occurrence and development of ASCVD., ${ }^{9,10}$ A crosssectional study conducted by our team in a community population also showed a negative correlation between health metrics and levels of highly sensitive C-reactive protein (hs-CRP), a classic indicator of human inflammation, but a causal relationship between the two has not been confirmed. ${ }^{11}$ In the present study, we intended to investigate the impact of ideal cardiovascular health metrics on plasma levels of hs-CRP in a large Chinese cohort.

\section{Methods}

\section{Study Design and Population}

This prospective study was conducted from April 2012 to June 2016 in the Kailuan community of Tangshan, a city in North China which is located in the north of Hebei province, surrounding the capital of China. Citizens over the age of 18 years in the Kailuan community were invited to participate in this study, but were excluded if the following conditions applied: data missing; hs-CPR level $>10$ $\mathrm{mg} / \mathrm{L}$; those with concomitant diseases, including infectious diseases, cancer, hematological disease, autoimmune disease, and severe hepatic or renal dysfunction; and those with a history of taking immunosuppressive agents, trauma or operation in the 3 months before the initiation of the study. All participants were asked to complete venous blood sample collection and testing, anthropometric measurements and a questionnaire survey at baseline. At the end of the follow-up, participants were recalled to repeat the same process as at baseline. The contents and purposes of this study were thoroughly explained to the participants prior to the study, and written consent was obtained from all of the participants. The study protocols were in accordance with the Declaration of Helsinki and ethical approval was obtained from the Science and Technology Committee of Tangshan city.

\section{Methods and Measurements}

\section{Anthropometric Measurement}

All staff were trained in standard procedures for measurement. Height and weight were measured to the nearest $0.1 \mathrm{~cm}$ and $0.1 \mathrm{~kg}$, respectively, with participants standing upright and barefoot in light clothes. Two separate measurements were performed for each subject and the average was used for analysis. Body mass index (BMI) was calculated as the ratio of weight to height squared $\left(\mathrm{kg} / \mathrm{m}^{2}\right)$. Blood pressure (BP) was measured in a sitting position and an average of two readings was used. However, when the two readings exhibited a difference greater than $5 \mathrm{mmHg}$, a third reading was necessary and the average of three readings was used.

\section{Determination of Biochemical Variables}

Participants were asked to fast overnight before venous blood sample collection from the veins of the forearm. Plasma samples were prepared by centrifugation at 3000 rpm for 10 minutes within 4 hours of blood collection. Total cholesterol (TC) and triglycerides (TG) were measured enzymatically, and fasting blood glucose (FBG) was measured using the hexokinase/glucose-6-phosphate dehydrogenase method (Mind Bioengineering Co., Shanghai, China).All biochemical variables were tested in the central laboratory of Kailuan Hospital on automatic biochemical analyzers (Hitachi 717; Hitachi, Tokyo, Japan).

\section{Determination of hs-CRP Levels}

The hs-CRP levels were measured using a commercial high-sensitivity immunonephelometric assay (Cias Latex CRP-H; Kanto Chemical Co., Tokyo, Japan) with a lower detection limit of $0.1 \mathrm{mg} / \mathrm{L}$. In-house intra-assay and interassay coefficients of variation (CVs) for hs-CRP were $6.48 \%$ and $4.92 \%$, respectively.

\section{Ideal Cardiovascular Health Metrics and Questionnaire Survey}

A structured questionnaire survey was administered to each participant face to face, on paper, to obtain demographic and behavior-associated information, including age, gender, smoking status, physical activity and salt intake. Smoking status was classified using self-reported information as "never", "former" or "current". Aerobic exercise was evaluated from responses to questions about the type and frequency of aerobic exercise during leisure time. We did not 
obtain the exact daily salt consumption (g/day) for every participant; salt intake was determined from responses to questions relating to salt preference, and was classified as "low," "medium" or "high". We used "low" salt intake $(8.7 \%)$ as a surrogate of ideal diet, consistent with the current guideline recommendations. According to a national nutrition survey published in 2019, a high-salt diet is a very serious problem in the dietary structure of Chinese residents, especially in northern China, where the population's daily salt intake is as high as $11.2 \mathrm{~g} .{ }^{12}$ Although other dietary problems also exist, such as inadequate intake of vegetables and fruits, these problems are less harmful to cardiovascular health. The questionnaire provided an approximation of whether an individual's diet was "ideal," "intermediate" or "poor". In addition, considering that the widely used cut-off value for normal weight in China is BMI $\leq 24 \mathrm{~kg} / \mathrm{m}^{2}$, the ideal BMI in the present study was defined as BMI $\leq 24 \mathrm{~kg}$ / $\mathrm{m}^{2}$, which is different from the AHA definition.

\section{Statistics}

Continuous variables were presented as mean and standard deviation (SD), and categorical variables were presented as frequency (proportions). Continuous variables were compared with a two-sample Student's $t$ test or non-parametric tests based on distributional properties. Categorical variables were compared with the chi-squared test. To investigate the potential correlation of each ideal health metric with plasma hs-CRP levels, multiple Cox proportional hazards models were established to determine whether or not the plasma level of hs-CRP had increased at the end of follow-up time compared with baseline as the dependent variable. In model 1, gain or loss of each ideal health metric during follow-up was set as the independent variable; and in model 2 , the change in the total number of ideal health metrics that each individual had during follow-up was set as the independent variable. In addition, confounding factors such as age and gender were adjusted for in both models. For all the comparisons, the level of statistical significance was set at $P<0.05$, two-sided. SPSS version 19.0 was used for all statistical analyses.

\section{Results}

\section{Basic Characteristics and Prevalence of} Ideal Cardiovascular Health Metrics in All

\section{Participants}

Of the 89,169 participants who volunteered to participate in the study, 8201 were excluded at baseline. Of those, 4362 had missing or incomplete data; 1462 had baseline hs-CPR level $>10 \mathrm{mg} / \mathrm{L} ; 1541$ had concomitant diseases, as previously described in the subsection "Study Design and Population"; and 836 had a history of taking immunosuppressants, trauma or operation in the 3 months before the study was initiated. Finally, 80,968 were enrolled in the current study at baseline and 76,523 (94.51\%) finished the follow-up investigation. The average follow-up time was 4.1 years.

The prevalence of each cardiovascular health metric in the total population and subgroups at baseline and the end of follow-up, by gender, is shown in Table 1. The proportions of participants who had ideal cardiovascular health metrics were as follows (baseline vs the end of follow-up): BP, $32.20 \%$ vs $32.48 \%$; TC, $54.60 \%$ vs $62.31 \%$; FBG, $67.64 \%$ vs $61.48 \%$; BMI, $51.24 \%$ vs $52.42 \%$; smoking status, $59.99 \%$ vs $67.06 \%$; aerobic exercise, $0 \%$ vs $9.21 \%$; salt intake, $8.75 \%$ vs $13.51 \%$. The proportions of ideal BP and TC were higher in men at baseline and at the end of the follow-up, while the proportions of ideal smoking, physical exercise and salt intake were higher in women. The proportions of ideal FBG and BMI were higher in women at baseline, but the difference between men and women disappeared at the end of the follow-up time.

\section{Plasma Levels of hs-CRP with the Change in Ideal Cardiovascular Health Metrics}

Figure 1 shows the changes in hs-CRP levels in participants who lost or gained different numbers of the ideal health metrics at the end of the follow-up compared with the baseline. The average hs-CRP level in participants who gained one, two, three, four, and five or six health metrics decreased by $0.142 \pm 0.021,0.311 \pm 0.032, \quad 0.418 \pm 0.044$, $0.518 \pm 0.071$ and $0.560 \pm 0.019(\mathrm{mg} / \mathrm{L})$, respectively. In contrast, compared with baseline, the average level of hsCRP in participants who lost one, two, three, four, and five or six health metrics increased by $0.162 \pm 0.023,0.284$ $\pm 0.033,0.459 \pm 0.063,0.582 \pm 0.114$ and $0.715 \pm 0.379$ (mg/ L), respectively.

\section{Multiple Cox Proportional Hazards Model for the Impact of Changes in Ideal Cardiovascular Health Metrics on hs-CRP Levels}

The potential association of losing or gaining each health metric with the plasma levels of hs-CRP was explored by multiple Cox proportional hazards models, with those 
Table I Basic Characteristics of Participants in the Present Study at Baseline and the End of Follow-Up

\begin{tabular}{|c|c|c|c|c|c|c|c|c|}
\hline & \multicolumn{3}{|l|}{ Baseline } & \multirow[b]{2}{*}{$P$} & \multicolumn{3}{|l|}{ Follow-up } & \multirow[b]{2}{*}{$P$} \\
\hline & $\begin{array}{l}\text { Men } \\
(n=60,931)\end{array}$ & $\begin{array}{l}\text { Women } \\
(n=15,592)\end{array}$ & $\begin{array}{l}\text { All } \\
(n=76,523)\end{array}$ & & $\begin{array}{l}\text { Men } \\
(n=60,931)\end{array}$ & $\begin{array}{l}\text { Women } \\
(n=15,592)\end{array}$ & $\begin{array}{l}\text { All } \\
(n=76,523)\end{array}$ & \\
\hline $\mathrm{SBP}(\mathrm{mmHg})$ & $124.89 \pm 20.92$ & $132.82 \pm 20.74$ & $131.2 \pm 21.02$ & 0.000 & $130.52 \pm 19.54$ & $129.62 \pm 19.02$ & $129.81 \pm 19.13$ & 0.000 \\
\hline $\mathrm{DBP}(\mathrm{mmHg})$ & $79.64 \pm 11.06$ & $84.85 \pm \mid 1.81$ & $83.79 \pm 11.85$ & 0.000 & $83.45 \pm 10.62$ & $83.25 \pm 10.47$ & $83.29 \pm 10.5$ & 0.041 \\
\hline $\mathrm{TC}(\mathrm{mmol} / \mathrm{L})$ & $4.99 \pm 1.05$ & $4.98 \pm 1.12$ & $4.98 \pm 1.11$ & 0.277 & $5.01 \pm 1.66$ & $4.98 \pm 1.55$ & $4.99 \pm 1.57$ & 0.023 \\
\hline FBG (mmol/L) & $5.3 \pm 1.59$ & $5.54 \pm 1.68$ & $5.49 \pm 1.67$ & 0.000 & $5.71 \pm 1.9$ & $5.67 \pm 1.98$ & $5.68 \pm 1.96$ & 0.012 \\
\hline BMI $\left(\mathrm{kg} / \mathrm{m}^{2}\right)$ & $24.61 \pm 3.74$ & $25.14 \pm 3.4$ & $25.03 \pm 3.48$ & 0.000 & $24.93 \pm 3.32$ & $24.94 \pm 3.33$ & $24.94 \pm 3.33$ & 0.656 \\
\hline $\mathrm{BP}(\mathrm{mmHg})$ & & & & 0.343 & & & & 0.000 \\
\hline $\begin{array}{l}\text { Ideal }(<120 / 80 \text { without } \\
\text { medication) }\end{array}$ & $19,670(32.28)$ & $4968(31.86)$ & $24,638(32.20)$ & & $20,071(32.94)$ & $4786(30.69)$ & $24,857(32.48)$ & \\
\hline $\begin{array}{l}\text { Intermediate } \\
(120-139 / 80-90 \text { or treated to } \\
<120 / 80)\end{array}$ & $17,869(29.33)$ & $4540(29.12)$ & $22,409(29.28)$ & & $19,175(31.47)$ & $4528(29.04)$ & $23,703(30.98)$ & \\
\hline $\begin{array}{l}\text { Poor }(\geq 140 / 90 \text { or treated to } \\
\geq 120 / 80)\end{array}$ & $23,392(38.39)$ & $6084(39.02)$ & $29,476(38.52)$ & & 21,685 (35.59) & $6278(40.27)$ & $27,963(36.54)$ & \\
\hline $\mathrm{TC}(\mathrm{mg} / \mathrm{dL})$ & & & & 0.000 & & & & 0.003 \\
\hline $\begin{array}{l}\text { Ideal }(<200 \text { without } \\
\text { medication) }\end{array}$ & 33,781 (55.44) & $7999(51.3)$ & $41,780(54.60)$ & & $38,136(62.59)$ & $9542(61.2)$ & $47,678(62.31)$ & \\
\hline $\begin{array}{l}\text { Intermediate }(200-239 \text { or } \\
\text { treated to }<200)\end{array}$ & 15,439 (25.34) & $3662(23.49)$ & $19,10 \mid(24.96)$ & & $15,942(26.16)$ & $4182(26.82)$ & $20,124(26.3)$ & \\
\hline $\begin{array}{l}\text { Poor }(\geq 240 \text { or treated to } \\
\geq 200)\end{array}$ & II,7II (19.22) & $3930(25.21)$ & $|5,64|(20.44)$ & & $6853(11.25)$ & $1868(11.98)$ & 8721 (II.4) & \\
\hline $\mathrm{FBG}(\mathrm{mg} / \mathrm{dL})$ & & & & 0.019 & & & & 0.346 \\
\hline $\begin{array}{l}\text { Ideal }(<100 \text { without } \\
\text { medication) }\end{array}$ & $41,070(67.4)$ & $10,693(68.58)$ & $51,763(67.64)$ & & $37,462(61.48)$ & $9587(61.49)$ & $47,049(61.48)$ & \\
\hline $\begin{array}{l}\text { Intermediate }(100-125 \text { or } \\
\text { treated to }<100)\end{array}$ & $13,989(22.96)$ & $3439(22.06)$ & $17,428(22.77)$ & & $|7,15|(28.15)$ & $4332(27.78)$ & $21,483(28.07)$ & \\
\hline $\begin{array}{l}\text { Poor }(\geq 126 \mathrm{mg} / \mathrm{L} \text { or treated } \\
\text { to } \geq 100)\end{array}$ & $5872(9.64)$ & $1460(9.36)$ & $7332(9.58)$ & & $6319(10.37)$ & $1673(10.73)$ & $7992(10.44)$ & \\
\hline BMI $\left(\mathrm{kg} / \mathrm{m}^{2}\right)$ & & & & 0.000 & & & & 0.071 \\
\hline Ideal $(<24)$ & $30,245(49.64)$ & $8968(57.5 \mathrm{I})$ & $39,213(51.24)$ & & $31,926(52.4)$ & $8187(52.51)$ & $40,113(52.42)$ & \\
\hline Intermediate (24-27.9) & $25,365(41.63)$ & $5067(32.5)$ & $30,432(39.77)$ & & $23,231(38.13)$ & $5961(38.23)$ & $29,192(38.15)$ & \\
\hline Poor $(\geq 28)$ & $5321(8.73)$ & 1558 (9.99) & $6879(8.99)$ & & $5774(9.48)$ & $1443(9.26)$ & $7217(9.43)$ & \\
\hline Smoking (n, \%) & & & & 0.000 & & & & 0.330 \\
\hline Ideal (never) & $31,015(50.9)$ & 14,889 (95.49) & $45,904(59.99)$ & & $40,888(67.11)$ & $10,428(66.88)$ & $51,316(67.06)$ & \\
\hline Intermediate (former, quit) & $4038(6.63)$ & $68(0.43)$ & $4106(5.37)$ & & $1832(3.01)$ & $440(2.82)$ & $2272(2.97)$ & \\
\hline Poor (current) & $25,877(42.47)$ & $635(4.08)$ & $26,512(34.65)$ & & $|8,21|(29.89)$ & $4724(30.29)$ & $22,935(29.97)$ & \\
\hline Aerobic exercise (n, \%) & & & & 0.000 & & & & 0.007 \\
\hline Ideal ( $\geq 150 \mathrm{~min} /$ week) & $0(0)$ & $0(0)$ & $0(0)$ & & $5519(9.06)$ & $1532(9.83)$ & $7051(9.21)$ & \\
\hline $\begin{array}{l}\text { Intermediate }(0-150 \mathrm{~min} / \\
\text { week) }\end{array}$ & $43,613(71.58)$ & $12,423(79.68)$ & $56,036(73.23)$ & & $4 I, 54 \mid(68.18)$ & $10,597(67.96)$ & $52,138(68.13)$ & \\
\hline Poor (none) & $|7,3| 8(28.42)$ & $3169(20.32)$ & $20,487(26.77)$ & & $|3,87|$ (22.76) & $3463(22.21)$ & $17,334(22.65)$ & \\
\hline
\end{tabular}

(Continued) 
Table I (Continued).

\begin{tabular}{|c|c|c|c|c|c|c|c|c|}
\hline \multirow[b]{2}{*}{ Salt intake (n, \%) } & \multicolumn{3}{|l|}{ Baseline } & \multirow[b]{2}{*}{0.000} & \multicolumn{3}{|l|}{ Follow-up } & \multirow[b]{2}{*}{0.000} \\
\hline & & & & & & & & \\
\hline Ideal (low salt) & $5343(8.77)$ & $1349(8.65)$ & $6692(8.75)$ & & $7956(13.06)$ & $2382(15.28)$ & $10,338(\mid 3.51)$ & \\
\hline Intermediate (medium salt) & $47,233(77.52)$ & $|2,8| \mid(82.16)$ & $60,044(78.47)$ & & $48,658(79.86)$ & $11,946(76.62)$ & $60,604(79.2)$ & \\
\hline Poor (high salt) & 8355 (13.7I) & 1432 (9.19) & 9787 (12.79) & & $4317(7.08)$ & $1264(8.11)$ & $558 \mid(7.29)$ & \\
\hline hs-CRP & $2.73 \pm 0.98$ & $2.40 \pm 1.05$ & $2.66 \pm 1.01$ & 0.000 & $3.02 \pm 1.08$ & $2.64 \pm 1.11$ & $2.94 \pm 1.09$ & 0.000 \\
\hline
\end{tabular}

Note: $P$ values indicate the comparative results between men and women at baseline or the end of follow-up.

Abbreviations: SBP, systolic blood pressure; DBP, diastolic blood pressure; BP, blood pressure; TC, total cholesterol; FBG, fasting blood glucose; BMI, body mass index; hsCRP, highly sensitive C-reactive protein.

keeping the corresponding health metric unchanged as a control. As shown in Figure 2A and 2B, BMI had the closest relationship with hs-CRP level in both men and women. Losing ideal BMI during the follow-up time raised the probability of hs-CRP increase by $1.72[95 \%$ confidence interval (CI), 1.59-1.86] times for men and 2.05 (95\% CI, 1.76-2.39) times for women, while gaining it decreased the probability by $0.55(95 \% \mathrm{CI}, 0.51-0.60)$ times for men and 0.43 (95\% CI, 0.37-0.50) times for women. Similarly, changes in ideal aerobic exercise, smoking and TC were all significantly associated with the risk of hs-CRP increase. The association of ideal salt intake with hs-CRP levels was more significant in men than in women, especially when it was lost during followup. As for the change in ideal BP during follow-up time, loss of ideal BP was associated with a significant rise in

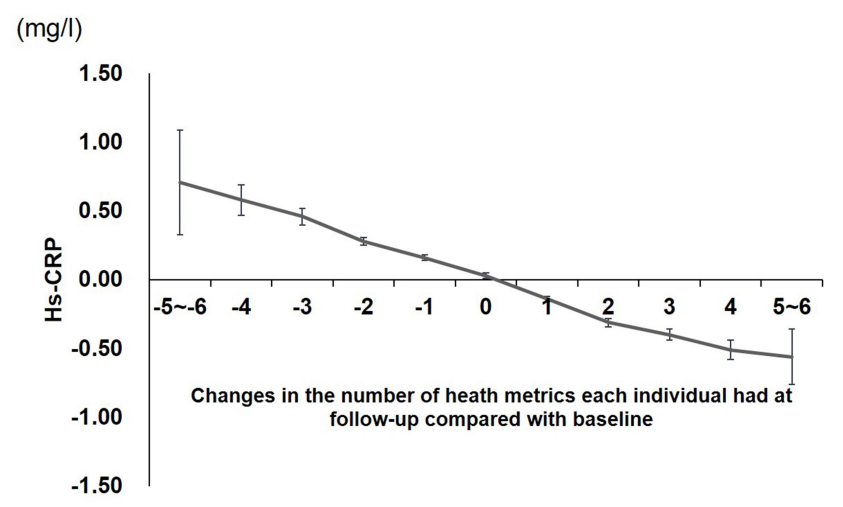

Figure I Changes in values of plasma hs-CRP at the end of follow-up compared with baseline in participants who lost or gained one to six health metrics during that period. The vertical axis represents the changed values of hs-CRP at the end of follow-up compared with baseline. The horizontal axis represents the change in the total number of health metrics that each individual had at the end of follow-up compared with baseline: 0 indicates that the total number of health metrics did not change; positive values $(+1$ to +6$)$ indicate that the number of health metrics increased; negative values $(-1$ to -6$)$ indicate that the number of health metrics decreased.

Abbreviation: hs-CRP, highly sensitive C-reactive protein. the chance of hs-CRP increasing (HR: $1.12,95 \% \mathrm{CI}, 1.07-$ 1.17 for men; HR: $1.25,95 \%$ CI, $1.15-1.37$ for women), while gain of ideal BP had no association with hs-CRP level. Surprisingly, changes in ideal FBG had no association with hs-CRP level in women, but gain of ideal FBG was significantly associated with a significant drop in the probability of hs-CRP increase in men (HR: $0.59,95 \% \mathrm{CI}$, 0.55-0.63).

The relationship of changes in the number of ideal health metrics during follow-up with hs-CRP levels is presented in Figure $3 \mathrm{~A}$ and $3 \mathrm{~B}$. When the number of ideal health metrics that individuals had increased from one to six, an obvious cumulative association with change in hs-CRP level was observed for both men and women (Table 2) and the HR values for risk of rising hs-CRP decreased from 0.57 (95\% CI, 0.51-0.64) to 0.84 (95\% CI, $0.80-0.87)$ for men and from 0.61 (95\% CI, $0.44-0.85)$ to 0.84 (95\% CI, $0.76-0.91)$ for women. Very similarly to this, the decrease in the number of health metrics of individuals also had a significant cumulative association with hs-CRP levels.

\section{Discussion}

This study intended to clarify the relationship between changes in ideal cardiovascular health metrics and hs-CRP levels in order to suggest a mechanism for promoting ideal cardiovascular health, as defined by the AHA Committee, to reduce cardiovascular events. The results show a close relationship of the seven cardiovascular health factors and behaviors included in the definition of ideal cardiovascular health with hs-CRP levels in the human body.

The incidence of cardiovascular disease in China has continued to grow rapidly over the years, and the highest point has not yet been reached. ${ }^{2,5}$ As one of the largest cohorts dedicated to cardiovascular disease prevention and control in China, the Kailuan Study has been focusing on 
A

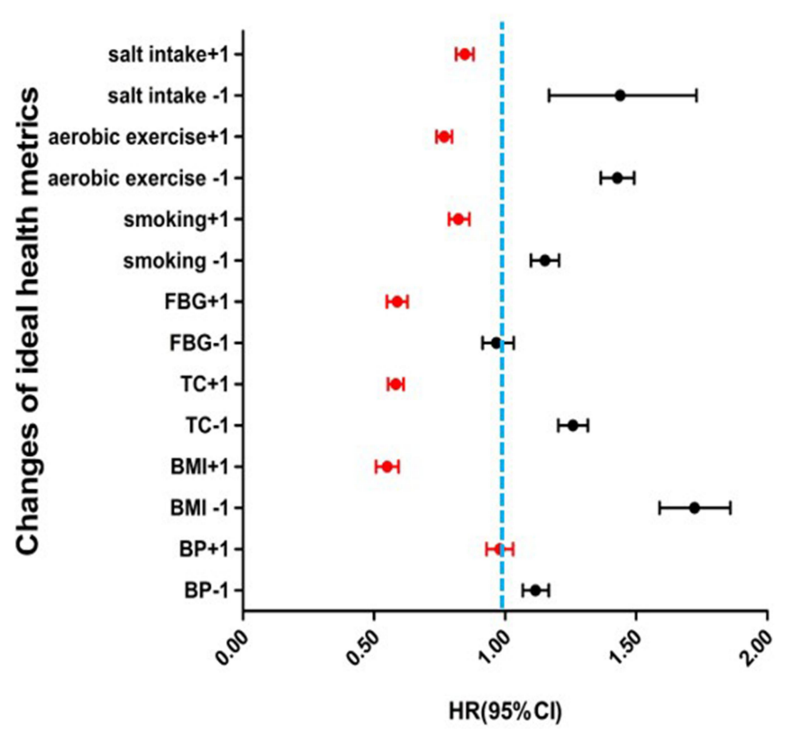

B

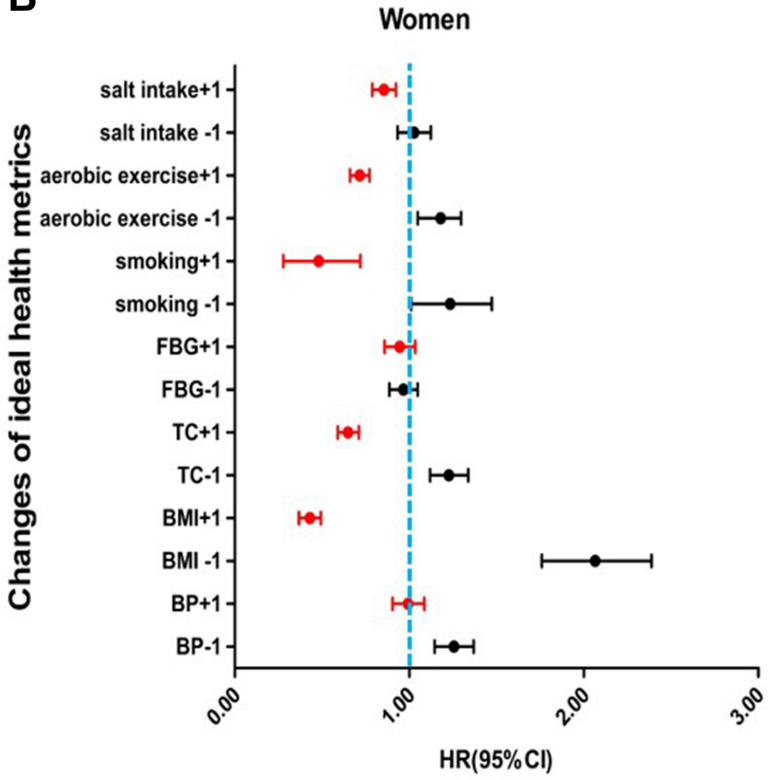

Figure 2 Hazard ratios of each health metric on plasma hs-CRP levels in men $(\mathbf{A})$ and women $(\mathbf{B}) .+1$ indicates that the health metric presented was gained at the end of follow-up compared with baseline; $-I$ indicates that the health metric presented was lost at the end of follow-up compared with baseline.

Abbreviations: hs-CRP, highly sensitive C-reactive protein; BP, blood pressure; BMI, body mass index; TC, total cholesterol; FBG, fasting blood glucose; HR, hazard ratio; $\mathrm{Cl}$, confidence interval.

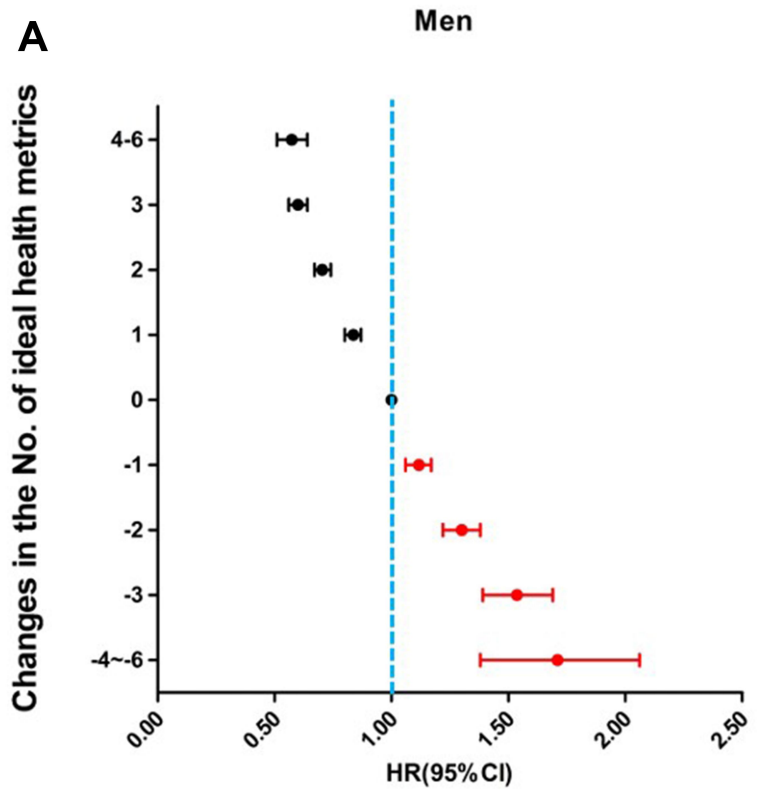

B

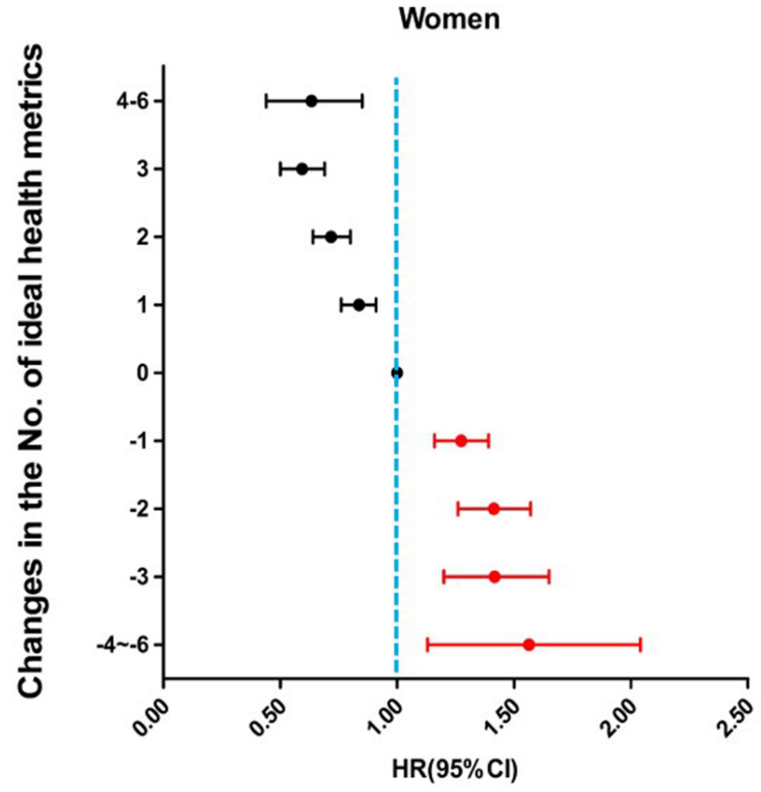

Figure 3 Hazard ratios of change in the number of health metrics on plasma hs-CRP levels in men $(\mathbf{A})$ and women $(\mathbf{B})$. Positive values $(+I$ to +6$)$ indicate that the number of health metrics increased at the end follow-up compared with baseline; negative values $(-I$ to -6$)$ indicate that the number of health metrics decreased at the end follow-up compared with baseline.

Abbreviations: hs-CRP, highly sensitive $\mathrm{C}$-reactive protein; $\mathrm{HR}$, hazard ratio; $\mathrm{Cl}$, confidence interval.

the relationship between cardiovascular disease-related factors and behaviors and the incidence of cardiovascular events in the Kailuan community for more than a decade. According to the data of the present study, the prevalence of ideal health metrics in the Kailuan community was mildly improved during the follow-up. With the exception of ideal FBG, the prevalence of all other ideal health metrics has increased; in particular, ideal smoking status, 
Table 2 Hazard Ratios of the Changes in Number of Ideal Health Metrics an Individual Had During Follow-Up on Plasma hs-CRP Levels in Men and Women

\begin{tabular}{|c|c|c|c|c|c|c|}
\hline \multirow[t]{2}{*}{ Change in No. of Ideal Health Metrics* } & \multicolumn{2}{|l|}{ Men } & \multicolumn{2}{|c|}{ Women } & \multicolumn{2}{|c|}{ Total } \\
\hline & HR & $95 \% \mathrm{Cl}$ & HR & $95 \% \mathrm{Cl}$ & HR & $95 \% \mathrm{Cl}$ \\
\hline 4 to 6 & 0.84 & $0.80-0.87$ & 0.84 & $0.76-0.91$ & 0.84 & $0.80-0.87$ \\
\hline 3 & 0.70 & $0.67-0.74$ & 0.71 & $0.64-0.8$ & 0.70 & $0.67-0.74$ \\
\hline 2 & 0.60 & $0.56-0.64$ & 0.59 & $0.50-0.69$ & 0.60 & $0.56-0.64$ \\
\hline I & 0.57 & $0.5 \mathrm{I}-0.64$ & 0.61 & $0.44-0.85$ & 0.58 & $0.52-0.65$ \\
\hline 0 & 1 & - & I & - & I & - \\
\hline-1 & 1.12 & $1.06-1.17$ & 1.27 & $1.16-1.39$ & 1.15 & $1.10-1.20$ \\
\hline-2 & 1.30 & $1.22-1.38$ & $\mathrm{I} .4 \mathrm{I}$ & $1.26-1.57$ & 1.32 & $1.25-1.40$ \\
\hline-3 & 1.53 & $1.39-1.69$ & 1.40 & $1.20-1.65$ & 1.49 & $1.37-1.62$ \\
\hline-4 to -6 & 1.69 & $1.38-2.06$ & 1.52 & $1.13-2.04$ & 1.62 & $1.38-1.92$ \\
\hline
\end{tabular}

Notes: *The data in this column indicate the changed number of ideal cardiovascular health metrics one individual had at the end of follow-up compared with that at baseline. Positive values indicate an increase and negative values indicate a decrease.

Abbreviations: hs-CRP, highly sensitive $\mathrm{C}$-reactive protein; $\mathrm{HR}$, hazard ratio; $\mathrm{Cl}$, confidence interval.

aerobic exercise and salt intake increased by $7.07 \%$, $9.21 \%$ and $4.76 \%$, respectively. However, we have to note that the improvement was not very impressive, and the prevention and control of cardiovascular risk factors are still very serious challenges. In addition, the prevalence characteristics of the health metrics in the present study are slightly different from those reported in populations from other regions in China. For example, compared with a 2018 report in a Northwest China population, ${ }^{13}$ the average levels of TC and FBG are slightly higher (4.68 vs $4.99 \mathrm{mmol} / \mathrm{L}$ for $\mathrm{TC}$ and $5.33 \mathrm{vs} 5.68 \mathrm{mmol} / \mathrm{L}$ for $\mathrm{FBG}$ ) but the BMI is lower $\left(25.14 \mathrm{vs} 24.94 \mathrm{~kg} / \mathrm{m}^{2}\right)$ in our study, which may be due to the huge differences in eating habits between the populations of North and South China. ${ }^{14}$ Since anti-hypertensive agents are free in the Kailuan community, the average blood pressure level in our study is much better than that reported in a nation-wide survey. ${ }^{15}$

It has been documented that many cardiovascular healthrelated factors and behaviors, such as physical exercise, ${ }^{16,17}$ blood pressure levels ${ }^{18,19}$ and salt intake, ${ }^{20}$ can affect the inflammatory state in the human body. Metabolic syndrome, the aggregation of the most classic risk factors for cardiovascular-metabolic diseases, was also found to be closely correlated with plasma hs-CRP levels. ${ }^{21}$ However, most of those studies were cross-sectional surveys, from which we could not draw a clear causal and dynamic picture about the relationships between ideal cardiovascular health metrics and inflammatory state in the body. Based on data from a large cohort in the North
China population, our study clearly shows that controlling BMI, TC, smoking and salt intake, and increasing exercise, could reduce plasma hs-CRP levels. In addition, our study shows that the number of health metrics was significantly correlated with the level of hs-CRP. One previous study conducted in Kailuan communities showed a strong inverse relationship between the cumulative incidence of cardiovascular diseases and the number of ideal health metrics that one individual had. ${ }^{7}$ Considering that chronic inflammation plays an important role in the formation of atherosclerosis, our results strongly suggest that the decline in incidence of ASCVD, by promoting ideal cardiovascular heath metrics, was mediated by the decreased level of systemic inflammation, at least in part.

Our study also obtained some other interesting results. $\mathrm{CRP}$ has long been considered an independent risk factor for hypertension. ${ }^{18,19,22}$ Our study demonstrated that gaining ideal BP during follow-up could significantly decrease hsCRP levels, which is consistent with some studies claiming a decrease in CRP levels observed after using antihypertensive drugs. ${ }^{23,24}$ But, to make the relationship between hypertension and hs-CRP more complicated, losing ideal BP, which means increased BP level, did not lead to elevated hs-CRP levels in the present study. Our study indicated no significant association between changes in ideal FBG and plasma hsCRP levels in women. However, in men, gaining an ideal FBG could decrease hs-CRP levels, but losing it failed to increase hs-CPR levels. Guerrero-Romero et al observed a 
significant relationship between CRP and FBG in those with impaired glucose tolerance but the significance disappeared in people with normal glucose tolerance. ${ }^{25}$ An Asian population-based study found that the correlation between logtransformed hs-CRP and FBG in people with apparently normal FBG failed to reach statistical significance. ${ }^{26} \mathrm{We}$ think that the association of hs-CRP levels and FBG is weak, considering the large sample size of our study. Since it has been well documented that high CRP levels can predict new type 2 diabetes, ${ }^{27,28}$ the potential relationship between postprandial blood glucose and hs-CRP levels needs further confirmation.

Our study has several limitations. First of all, all the participants of the study are employees and retirees of Kailuan (Group) Co. Ltd, which has grown from an initial coal-mining industry to a large enterprise group involving many fields, such as real estate, textiles and construction, which led to significant skewness in the gender distribution. We would therefore take a cautious attitude in extrapolating the findings of our study to other populations. Second, of all the 117,822 employees and retirees who were invited to participate, $75.68 \%$ volunteered. Although the mean age of cohort participants was comparable with that of the whole population, according to the medical records of Kailuan (Group) Co. (57.63 vs 57.61 years) which indicated good representativeness of the cohort used in the study, we cannot rule out that the selection bias and health status of the enrolled people may be slightly worse than the real population, considering that relatively healthy people are more likely to refuse to participate. Third, this study did not make an accurate assessment of the ideal diet, but replaced it with daily salt intake, and the method for assessing salt intake was not very accurate. We acknowledge that this would have an unpredictable effect on the research results, although this effect may be minor.

\section{Conclusions}

This study used data from a large cohort in a population in North China to confirm the close relationship between ideal health metrics defined by the AHA Committee in 2010 and plasma hs-CRP levels, the indicator of systemic inflammation, at least partially revealing the mechanism by which ideal health metrics bring cardiovascular benefits. The increase or decrease in a single metric for most ideal health metrics, as well as the change in the total number of ideal health metrics that individuals had, can cause significant fluctuations in hs-CRP levels. Advocating a lifestyle with more ideal health metrics and other methods that may reduce the body's chronic inflammation levels remain indispensable measures for the prevention and control of cardiovascular disease in China.

\section{Acknowledgments}

We thank all the staff and participants of the Kailuan Study for their important contributions to data collection.

\section{Funding}

This study was funded by grants from the National Key R\&D Program of China (Grant No. 2018YFC1311404); the 12th Five-Year Science and Technology Support Program of China (Grant No. 2013BAI06B02); the Cultivation Fund of the First Affiliated Hospital of Chongqing Medical University (Grant No. PYJJ2017-28; PYJJ2018-16).

\section{Disclosure}

The authors report no conflicts of interest for this work.

\section{References}

1. Stevens W, Peneva D, Li JZ, et al. Estimating the future burden of cardiovascular disease and the value of lipid and blood pressure control therapies in China. BMC Health Serv Res. 2016;16(1):175. doi:10.1186/s12913-016-1420-8

2. Yang G, Wang Y, Zeng Y, et al. Rapid health transition in China, 1990-2010: findings from the Global Burden of Disease Study 2010. Lancet. 2013;381(9882):1987-2015. doi:10.1016/S0140-6736(13) 61097-1

3. Yan R, Li W, Yin L, et al. Cardiovascular Diseases and Risk-Factor Burden in Urban and Rural Communities in High-, Middle-, and Low-Income Regions of China: A Large Community-Based Epidemiological Study. J Am Heart Assoc. 2017;6(2). doi:10.1161/ JAHA.116.004445.

4. Xi B, Liu F, Hao Y, et al. The growing burden of cardiovascular diseases in China. Int J Cardiol. 2014;174(3):736-737. doi:10.1016/j. ijcard.2014.04.098

5. Zhou M, Wang H, Zhu J, et al. Cause-specific mortality for 240 causes in China during 1990-2013: a systematic subnational analysis for the Global Burden of Disease Study 2013. Lancet. 2016;387 (10015):251-272. doi:10.1016/S0140-6736(15)00551-6

6. Lloyd-Jones DM, Hong Y, Labarthe D, et al. Defining and setting national goals for cardiovascular health promotion and disease reduction: the American Heart Association's strategic Impact Goal through 2020 and beyond. Circulation. 2010;121(4):586-613. doi:10.1161/ CIRCULATIONAHA.109.192703

7. Wu S, Huang Z, Yang X, et al. Prevalence of ideal cardiovascular health and its relationship with the 4-year cardiovascular events in a northern Chinese industrial city. Circ Cardiovasc Qual Outcomes. 2012;5(4):487-493. doi:10.1161/CIRCOUTCOMES.111.963694

8. Zhang Q, Zhou Y, Gao X, et al. Ideal cardiovascular health metrics and the risks of ischemic and intracerebral hemorrhagic stroke. Stroke. 2013;44 (9):2451-2456. doi:10.1161/STROKEAHA.113.678839

9. Huet F, Akodad M, Fauconnier J, et al. Anti-inflammatory drugs as promising cardiovascular treatments. Expert Rev Cardiovasc Ther. 2017;15(2):109-125. doi:10.1080/14779072.2017.1273771

10. Shayganni E, Bahmani M, Asgary S, et al. Inflammaging and cardiovascular disease: management by medicinal plants. Phytomedicine. 2016;23(11):1119-1126. doi:10.1016/j.phymed.2015.11.004 
11. Xue H, Wang J, Hou J, et al. Ideal cardiovascular health behaviors and factors and high sensitivity C-reactive protein: the Kailuan crosssectional study in Chinese. Clin Chem Lab Med. 2014;52(9):13791386. doi:10.1515/cclm-2013-0657

12. Tan M, He FJ, Wang C, et al. Twenty-Four-Hour Urinary Sodium and Potassium Excretion in China: A Systematic Review and MetaAnalysis. J Am Heart Assoc. 2019;8(14):e012923. doi:10.1161/ JAHA.119.012923

13. Sun L, Zou T, Wang BZ, et al. Epidemiological investigation into the prevalence of abnormal inter-arm blood pressure differences among different ethnicities in Xinjiang, China. PLoS One. 2018;13(1): e0188546. doi:10.1371/journal.pone.0188546

14. Wang Z, Gordon-Larsen P, Siega-Riz AM, et al. Sociodemographic disparity in the diet quality transition among Chinese adults from 1991 to 2011. Eur J Clin Nutr. 2017;71(4):486-493. doi:10.1038/ ejcn.2016.179

15. Bragg F, Li L, Smith M, et al. Associations of blood glucose and prevalent diabetes with risk of cardiovascular disease in 500000 adult Chinese: the China Kadoorie Biobank. Diabet Med. 2014;31 (5):540-551. doi:10.1111/dme.12392

16. Bergstrom G, Behre CJ, Schmidt C. Moderate intensities of leisuretime physical activity are associated with lower levels of high-sensitivity C-reactive protein in healthy middle-aged men. Angiology. 2012;63(6):412-415. doi:10.1177/0003319711423386

17. Abramson JL, Vaccarino V. Relationship between physical activity and inflammation among apparently healthy middle-aged and older US adults. Arch Intern Med. 2002;162(11):1286-1292. doi:10.1001/ archinte.162.11.1286

18. Sesso HD, Buring JE, Rifai N, et al. C-reactive protein and the risk of developing hypertension. JAMA. 2003;290(22):2945-2951. doi:10.1001/jama.290.22.2945

19. Wang TJ, Gona P, Larson MG, et al. Multiple biomarkers and the risk of incident hypertension. Hypertension. 2007;49(3):432-438. doi:10.1161/01.HYP.0000256956.61872.aa

20. Fogarty AW, Lewis SA, McKeever TM, et al. Is higher sodium intake associated with elevated systemic inflammation? A population-based study. Am J Clin Nutr. 2009;89(6):1901-1904. doi:10.3945/ ajen.2008.27006
21. Wen J, Liang Y, Wang F, et al. Association of C-reactive protein and metabolic syndrome in a rural Chinese population. Clin Biochem. 2009;42(10-11):976-983. doi:10.1016/j.clinbiochem.2009.03.026

22. Dauphinot V, Roche F, Kossovsky MP, et al. C-reactive protein implications in new-onset hypertension in a healthy population initially aged 65 years: the Proof study. J Hypertens. 2009;27(4):736743. doi:10.1097/HJH.0b013e328326f801

23. Fliser D, Buchholz K, Haller H, et al. Antiinflammatory effects of angiotensin II subtype 1 receptor blockade in hypertensive patients with microinflammation. Circulation. 2004;110(9):1103-1107. doi:10.1161/01.CIR.0000140265.21608.8E

24. Ridker PM, Danielson E, Rifai N, et al. Valsartan, blood pressure reduction, and C-reactive protein: primary report of the Val-MARC trial. Hypertension. 2006;48(1):73-79. doi:10.1161/01.HYP.0000226046.588 83.32

25. Guerrero-Romero F, Simental-Mendia LE, Rodriguez-Moran M. Association of C-reactive protein levels with fasting and postload glucose levels according to glucose tolerance status. Arch Med Res. 2014;45(1):70-75. doi:10.1016/j.arcmed.2013.11.004

26. Rhee EJ, Kim YC, Lee WY, et al. Comparison of insulin resistance and serum high-sensitivity C-reactive protein levels according to the fasting blood glucose subgroups divided by the newly recommended criteria for fasting hyperglycemia in 10059 healthy Koreans. Metabolism. 2006;55 (2):183-187. doi:10.1016/j.metabol.2005.08.010

27. Kashima S, Inoue K, Matsumoto M, et al. White blood cell count and c-reactive protein independently predicted incident diabetes: Yuport Medical Checkup Center Study. Endocr Res. 2019;1-11.

28. Sung KC, Ryu S, Sung JW, et al. Inflammation in the prediction of type 2 diabetes and hypertension in healthy adults. Arch Med Res. 2017;48(6):535-545. doi:10.1016/j.arcmed.2017.11.010
International Journal of General Medicine

\section{Publish your work in this journal}

The International Journal of General Medicine is an international, peer-reviewed open-access journal that focuses on general and internal medicine, pathogenesis, epidemiology, diagnosis, monitoring and treatment protocols. The journal is characterized by the rapid reporting of reviews, original research and clinical studies

\section{Dovepress}

across all disease areas. The manuscript management system is completely online and includes a very quick and fair peer-review system, which is all easy to use. Visit http://www.dovepress.com/ testimonials.php to read real quotes from published authors. 